\title{
Aplikasi Keliling Nusantara Edisi Sumatera Berbasis Android dan iOS
}

\author{
Angga Apridianto ${ }^{1)}$, Kodrat Iman Satoto ${ }^{2)}$, Ike Pertiwi Windasari ${ }^{2)}$ \\ Program Studi Sistem Komputer Fakultas Teknik Universitas Diponegoro \\ Jalan Prof. Sudharto, Tembalang, Semarang, Indonesia \\ ang.apridianto@gmail.com
}

\begin{abstract}
Diversity of art and culture in Indonesia should be preserved so as not to become extinct in the face of times so that it can be passed on to generations to come. Many of the people of Indonesia who forget about the culture to identity of the area because of several factors such as the people of indonesia more interested of the western culture than self culture, the region of Indonesia which large also cause people's reluctance to learn because of constrained of time, distance and cost as well as limitations of the media information about the art and culture that currently can only be learned through pictures and visit the location of art and culture directly make the introduction of art and culture to people of indonesia not yet optimal. Therefore required a media so that people can learn more about the wealth of art and culture without having to visit directly into the location of the arts and cultures its.

"Keliling Nusantara Edisi Sumatra" application that was built can be the way to preserve the national culture. The function of this application as a learning media for recognize the diversity of arts and cultures of Indonesia on the island of Sumatra. This application is built using Mobione Studio and running on Android and iOS devices. The application is made using the UCD (User Centered Design) which has been mapped to multimedia development methods by Luther from the stage specify the context of use and specify the users and organisational requirements are mapped into the concept, the stage produce design solutions are mapped into the design, production and collecting material as wellas the evaluate design againts the user requirements are mapped into the stage of testing and distribution.

The results produced an application based on Android and iOS contains folks song and lyrics and sound, traditional dress, traditional homes, custom traditions, traditional weapons, traditional dance, tradition musical instrument, the symbol of the region, the anniversaries, the name of the capital city, location, area and amount of population and the flora and fauna typical area on the island of Sumatra. The application goes well on the Android operating system version 2.2-4.X and iOS version 5-7 correspond with the functionality, specification and design of desired.
\end{abstract}

Keywords : mobile device, User Centered Design, Multimedia, Android, iOS, Mobione Studio, "Keliling Nusantara Edisi Sumatra" application.

\section{PENDAHULUAN}

$\mathrm{K}$ EANEKARAGAMAN seni dan budaya di Indonesia harus dilestarikan agar tidak punah ditelan zaman sehingga dapat diwariskan ke generasi yang akan datang. Banyak diantara masyarakat Indonesia yang sering melupakan kebudayaan yang menjadi identitas daerah tersebut karena beberapa faktor seperti lebih tertariknya masyarakat indonesia dengan kebudayaan barat dibandingkan dengan kebudayaan sendiri dan keterbatasan media informasi tentang seni budaya yang saat ini hanya dapat dipelajari melalui gambar atau mengunjungi lokasi seni budaya secara langsung membuat pengenalan seni budaya terhadap masyarakat Indonesia belum optimal. Oleh karena itu, diperlukan sebuah media agar masyarakat dapat mempelajari lebih jauh tentang kekayaan seni budaya yang ada di Indonesia tersebut tanpa harus berkunjung langsung ke lokasi seni dan budaya itu.

Dengan memanfaatkan perkembangan teknologi informasi, dilakukan sebuah penelitian dalam upaya pelesatarian seni dan budaya tersebut. Penelitian ini berupa pembuatan aplikasi Keliling Nusantara Edisi Sumatera berbasis Android dan iOS yang berisi tentang kekayaan seni dan budaya Indonesia di pulau Sumatera meliputi lagu daerah beserta lirik dan suaranya, pakaian adat, rumah adat, tradisi adat, senjata adat, tarian adat, alat musik adat, lambang daerah, hari jadi, nama ibu kota, letak, luas dan jumlah penduduk serta flora dan fauna khas daerah. Aplikasi ini dibuat dengan tujuan sebagai media pembelajaran dalam mengenalkan kekayaan seni dan budaya di Indonesia terutama di pulau Sumatera.

\section{TINJAUAN PUSTAKA}

\section{A. Metode UCD (User Centered Design)}

Metode UCD adalah metode penelitian yang filosofi perancangan dan proses pengembangan sistemnya berpusat pada pengguna ${ }^{[1]}$, sehingga hasil penelitian bisa lebih efektif dan efisien karena sesuai dengan kebutuhan aplikasi yang diinginkan oleh pengguna. Adapun tahapan dalam metode UCD berdasarkan ISO 13407:1999 ditunjukkan pada gambar 1. sebagai berikut ${ }^{[2]}$.

ISO 13407:1999 Human-centered design process for interactive systems

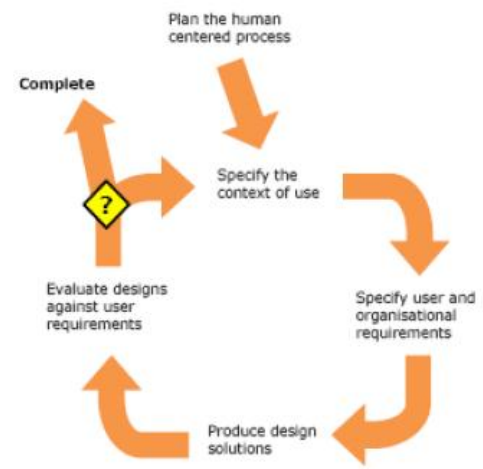

Gambar 1. Tahapan dalam metode UCD berdasarkan ISO 13407:1999 $9^{[2]}$ 
1. Specify the context of use, memahami dan menentukan konteks penggunaan.

2. Specify user and organisational requirements, menentukan kebutuhan pengguna.

3. Produce design solution, solusi perancangan yang dihasilkan.

4. Evaluate designs againts user requirements, evaluasi perancangan terhadap kebutuhan pengguna.

Terdapat beberapa metode pada pendekatan UCD yang dapat digunakan, antara lain: kuesioner, wawancara, observasi, task modeling, dan prototyping dengan kelebihan dan kekurangan masing-masing. Pemilihan metode dalam setiap proses UCD merupakan faktor penting yang sangat menentukan kualitas feedback dari pengguna, oleh karena itu diperlukan perencanaan metode apa yang dilakukan pada setiap proses UCD. Adapun hubungan dari masing-masing metode dengan tahapan atau aktivitas dalam UCD ditunjukkan pada gambar 2. sebagai berikut ${ }^{[4]}$.

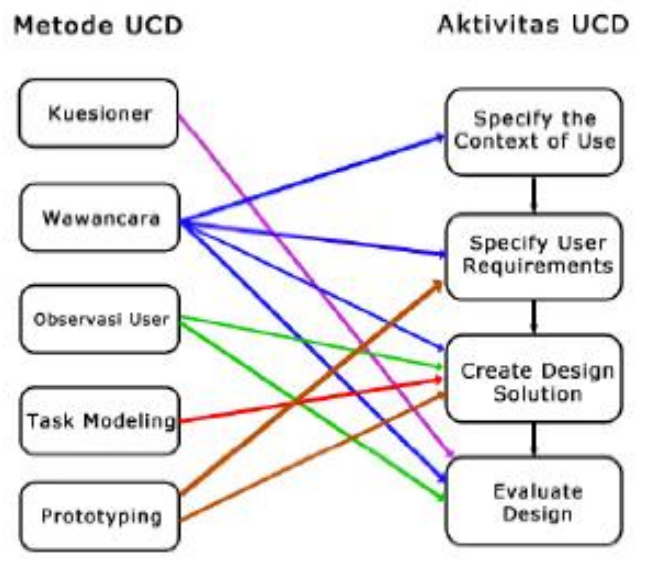

Gambar 2. Pemetaan metode UCD dengan aktivitas $\mathrm{UCD}^{[4]}$

\section{B. Metode Pengembangan Multimedia}

Multimedia adalah suatu kombinasi data atau media untuk menyampaikan suatu informasi sehingga informasi itu tersaji dengan lebih menarik, sedangkan menurut Oblinger multimedia didefinisikan sebagai penyatuan dua atau lebih media komunikasi seperti teks, grafik, animasi, audio dan video dengan ciri-ciri interaktifitas komputer untuk menghasilkan suatu presentasi yang menarik. Dalam multimedia, terkandung beberapa objek seperti teks, suara, video, gambar, dan animasi.

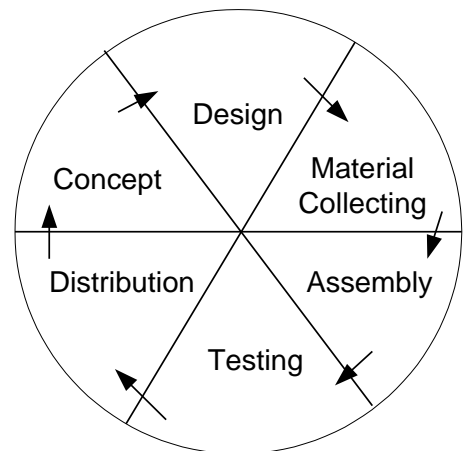

Gambar 3. Tahapan pengembangan multimedia menurut Luther ${ }^{[10]}$

Pengembangan multimedia menurut Luther dilakukan berdasarkan 6 tahap, yaitu: concept, design, material collecting, assembly, testing, dan distribution seperti yang terdapat pada gambar 3. di atas berikut penjelasannya ${ }^{[10]}$.

\section{Konsep (Concept)}

Dalam tahap konsep yang perlu diperhatikan adalah menentukan tujuan, termasuk identifikasi para pengguna, macam aplikasi (presentasi, interaktif, dan lain-lain), tujuan aplikasi (informasi, hiburan, dan lain-lain), dan spesifikasi umum serta memahami karakteristik pengguna aplikasi.

2. Perancangan (Design)

Maksud dari tahap perancangan adalah membuat spesifikasi secara rinci mengenai arsitektur proyek, gaya, dan kebutuhan meterial untuk proyek. Spesifikasi dibuat secara rinci sehingga pada tahap berikutnya yaitu pengumpulan bahan dan assembly tidak diperlukan keputusan baru tetapi menggunakan apa yang sudah ditentukan pada tahap perancangan atau desain. Perancangan berbasis multimedia dapat dibagi menjadi tiga macam yaitu desain berbasis multimedia, desain struktur navigasi dan desain berorientasi objek. Perancangan dapat menggunakan gabungan dari ketiga metode tersebut untuk mendapatkan gambaran dan pemahaman yang lengkap sehingga tahapan berikutnya lebih mudah untuk dikerjakan.

3. Pengumpulan Materi (Material Collecting)

Pada tahap ini dilakukan pengumpulan bahan seperti clipart image, animasi, pembuatan citra grafik, foto, audio dan lain-lain yang diperlukan untuk tahap berikutnya dalam pembangunan aplikasi.

4. Pembuatan (Assembly)

Tahap pembuatan merupakan tahap pembuatan seluruh objek multimedia. Pembuatan aplikasi berdasarkan storyboard, flowchart view, struktur navigasi, atau diagram objek yang berasal dari tahap desain.

5. Pengujian (Testing)

Pengujian dilakukan setelah tahap pembuatan selesai dan seluruh data telah dimasukkan. Pengujian dilakukan untuk memastikan apakah hasil dari aplikasi yang dibangun seperti yang diharapkan atau tidak.

6. Penyebaran (Distribution)

Tahap ini dilakukan apabila aplikasi akan disebarkan secara luas baik itu melalui penggandaan dengan menggunakan flashdisk maupun penyebaran menggunakan jaringan internet. Tahap penyebaran juga merupakan tahap evaluasi terhadap aplikasi tersebut guna pengembangan yang lebih baik di masa yang akan datang.

\section{Android}

Android merupakan platform mobile pertama yang lengkap, terbuka dan bebas. Berikut penjelasan dari masingmasing kriteria tersebut ${ }^{[9]}$.

1. Lengkap (Complete Platform)

Para desainer dapat melakukan pendekatan yang komprehensif ketika mereka sedang mengembangkan platform Android. Android merupakan sistem operasi yang aman dan banyak menyediakan tools dalam membangun software dan memungkinkan untuk peluang pengembangan aplikasi.

2. Terbuka (Open Source Platform)

Platform Android disediakan melalui lisensi open source. Pengembang dapat dengan bebas untuk mengembangkan aplikasi. Android sendiri menggunakan Linux Kernel 2.6.

3. Free (Free Platform)

Android adalah aplikasi yang bebas untuk dikembangkan. Tidak ada lisensi atau biaya royalti untuk pengembangan pada platform Android. Aplikasi Android dapat didistribusikan dan diperdagangkan dalam bentuk apa pun. 


\section{D. $i O S$}

iOS diturunkan dari OS X, yang memiliki fondasi Darwin dan karena itu iOS merupakan sistem operasi Unix. iOS adalah versi bergerak dari sistem operasi OS X yang dipakai di komputer-komputer Apple. Versi iOS dulunya berawal dari versi iPhone OS 1.0 (initial release) Juni 2007 untuk Iphone dan Ipod Touch hingga iPhone OS 3.1 - 3.2 versi terakhir dari nama iPhone OS pada September 2009. Pada Juni 2010 iPhone OS berganti nama menjadi iOS yang diterapkan pada iPhone, iPod touch, iPad yang telah menambahkan beberapa fitur yang menarik dan lebih interaktif sehingga menarik minat pengguna untuk menggunakannya ${ }^{[17]}$.

\section{E. Mobione Studio}

MobiOne Studio merupakan salah satu developer tools dari Genuitec. MobiOne Studio memiliki sembilan fitur utama yang memudahkan developer dalam mengembangkan aplikasi. MobiOne Studio dapat digunakan bukan hanya untuk membuat aplikasi di iOS namun juga di perangkat mobile lainnya seperti Android OS dalam bentuk native application atau web application ${ }^{[16]}$.

\section{METODE PENELITIAN}

Metode penelitian yang digunakan oleh penyusun dalam penyusunan laporan tugas akhir ini adalah penggabungan dari dua metode yaitu Metode User-Centered Design (UCD) dan Metode Pengembangan Multimedia Menurut Luther. Alasan dipilihnya metode UCD sebagai metode penelitian yang digunakan penyusun dikarenakan dengan menggunakan metode tersebut, penelitian bisa tepat guna sesuai dengan sasaran atau kebutuhan dari pengguna aplikasi sehingga produk yang dihasilkan lebih efektif dan efisien. Sedangkan alasan dipilihnya metode pengembangan multimedia menurut Luther dikarenakan metode tersebut cocok untuk pengembangan aplikasi interaktif seperti yang akan dibangun. Jika dilihat dari langkah-langkah kedua metode tersebut, kedua metode memiliki persamaan proses atau tahapan dalam membangun sebuah aplikasi sehingga kedua metode tersebut dapat dipetakan satu sama lain. Adapun hasil pemetaan kedua metode tersebut ditunjukan pada gambar 4 . sebagai berikut.

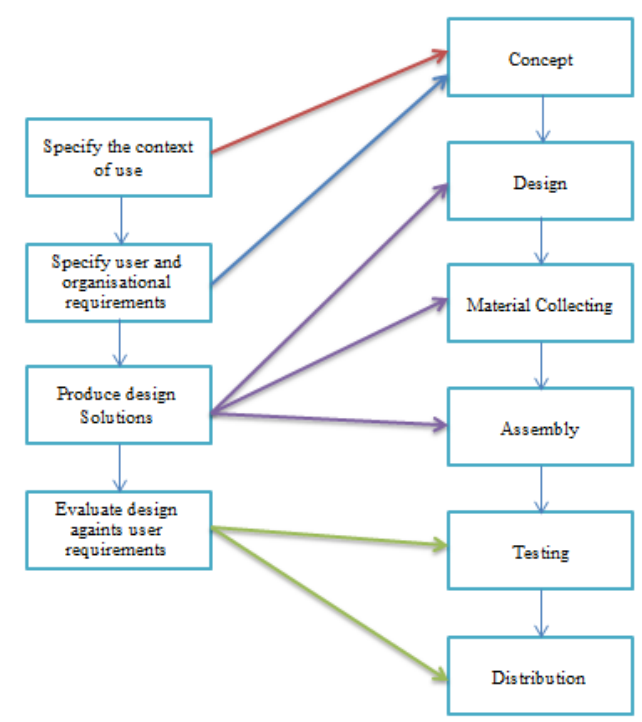

Gambar 4. Pemetaan Metode UCD dengan Metode Pengembangan Multimedia menurut Luther
Seperti pada gambar 4. di atas, tahapan specify the context of use dan specify user and organisational requirements dalam metode UCD dapat dipetakan ke dalam tahapan concept dalam metode pengembangan multimedia menurut Luther. Lalu untuk tahapan produce design solutions metode UCD dapat dipetakan ke dalam tahapan design, material collecting dan assembly pada metode pengembangan multimedia menurut Luther. Sedangkan untuk tahapan evaluate design againts user requirements dapat dipetakan ke dalam tahapan testing dan distribution.

\section{ANALISIS DAN PERANCANGAN APLIKASI}

\section{A. Analisis Aplikasi}

Sesuai dengan metode penelitian yang digunakan, tahapan pertama yang dilakukan dalam pembangunan aplikasi adalah tahapan specify the context of use dan specify user and organisational requirements yang telah dipetakan ke dalam tahapan concept (konsep).

\section{Konsep}

1. Aplikasi yang dibangun mengandung 4 elemen multimedia yaitu teks, gambar, suara dan animasi.

2. Aplikasi yang dibangun memiliki elemen seni dan budaya meliputi lagu adat yang disertai dengan lirik dan suara, pakaian adat, rumah adat, tradisi adat, senjata adat, tarian adat dan alat musik adat yang masing-masing diberikan dalam bentuk teks dan gambar dengan penjelasan di tiap kontennya.

3. Aplikasi yang dibangun memiliki fitur utama dan fitur tambahan. Untuk fitur utama aplikasi berupa materi pembelajaran yang dikemas dalam permainan sehingga dapat mengasah daya ingat sedangkan untuk fitur tambahan yang mendukung kinerja aplikasi berupa fitur pengiriman kritik dan saran pengembangan aplikasi kepada penyusun melalui email serta fitur berbagi aplikasi melalui media sosial meliputi facebook, twitter, google+ dan linkedin.

4. Aplikasi yang dibangun berbasis Android dan iOS dengan display portrait dan lanscape untuk masing-masing sistem operasi tersebut.

5. Aplikasi yang dibangun bersifat interaktif dengan pengguna seperti adanya fitur pemilihan karakter di dalam aplikasi yang akan memandu pengguna dalam mengoperasikan aplikasi, adanya petunjuk di setiap fitur permainan serta adanya nilai yang didapat pengguna jika berhasil menyelesaikan permainan.

6. Aplikasi yang dibangun menggunakan gambar kartun yang menarik dengan tujuan minat pengguna aplikasi akan bertambah.

7. Aplikasi yang dibangun tidak memerlukan koneksi internet dalam pengoperasiannya agar memperkecil kemungkinan error atau kesalahan pada aplikasi dalam mengakses konten seni dan budaya.

\section{Deskripsi Konsep}

Aplikasi Keliling Nusantara Edisi Sumatera terdiri dari fitur utama dan fitur tambahan. Fitur utama terdiri dari 2 bagian yaitu bagian pertama adalah pembelajaran dan bagian kedua adalah permainan. Pada bagian pembelajaran, aplikasi menampilkan konten-konten tentang seni dan budaya 10 provinsi yang ada di pulau Sumatera meliputi lagu adat, pakaian adat, rumah adat, tradisi adat, senjata adat, tarian adat dan alat musik adat, lambang daerah, hari jadi, nama ibu kota, letak, luas dan jumlah penduduk serta flora dan fauna khas masing-masing 10 provinsi tersebut. Pada bagian 
permainan, aplikasi menampilkan lima macam permainan yang disertai petunjuk di setiap permainannya antara lain permainan soal singkat, permainan pilihan ganda, permainan kuis, permainan soal bergambar serta permainan tebak gambar dan nada.

Selain fitur utama yang telah dijelaskan di atas, aplikasi juga memiliki fitur tambahan yang mendukung kinerja aplikasi seperti konten pengiriman kritik dan saran pengembangan aplikasi kepada penyusun melalui email serta konten berbagi aplikasi melalui media sosial meliputi facebook, twitter, google+ dan linkedin.

\section{B. Perancangan Aplikasi}

Perancangan aplikasi yang digunakan untuk membangun aplikasi ini hanya perancangan atau desain berbasis multimedia. Alasan hanya menggunakan perancangan berbasis multimedia karena hanya dengan menggunakan perancangan ini saja sudah cukup menggambarkan aplikasi secara lengkap dan menyeluruh baik itu obyek multimedia yang ada maupun hubungan interaktif antara obyek-obyek tersebut. Perancangan berbasis multimedia menggunakan perangkat storyboard dan flowchart view. Storyboard digunakan untuk multimedia linier dan flowchart view digunakan sebagai pelengkap storyboard untuk multimedia non-linier (interaktif).

\section{Storyboard}

Storyboard merupakan visualisasi ide dari aplikasi yang akan dibangun sehingga dapat memberikan gambaran aplikasi yang dihasilkan. Menurut Luther, storyboard merupakan deskripsi tiap scene (adegan) yang secara jelas menggambarkan objek multimedia serta perilakunya. Untuk storyboard aplikasi yang ditampilkan hanya 5 dari total keseluruhan perancangan yang telah dibuat Adapun storyboard yang ditampilkan tersebut adalah storyboard scene 4 baik itu untuk aplikasi Android maupun iOS, storyboard scene 15, storyboard scene 179 dan storyboard scene 184. Storyboard scene 4 untuk menu utama Android ditunjukkan pada gambar 5. sebagai berikut.

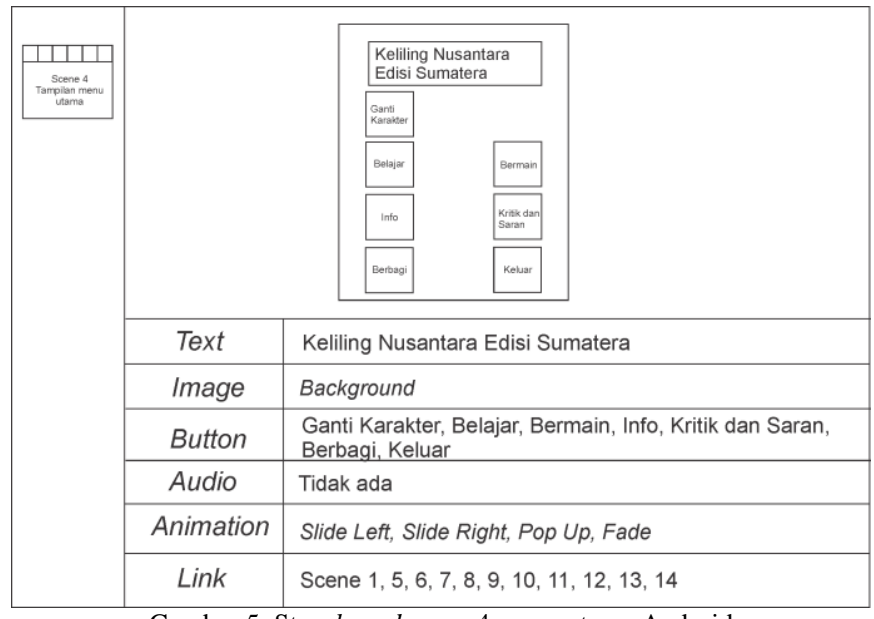

Gambar 5. Storyboard scene 4 menu utama Android

Lalu storyboard scene 4 yang merupakan perancangan menu utama iOS ditunjukkan pada gambar 6. sebagai berikut.

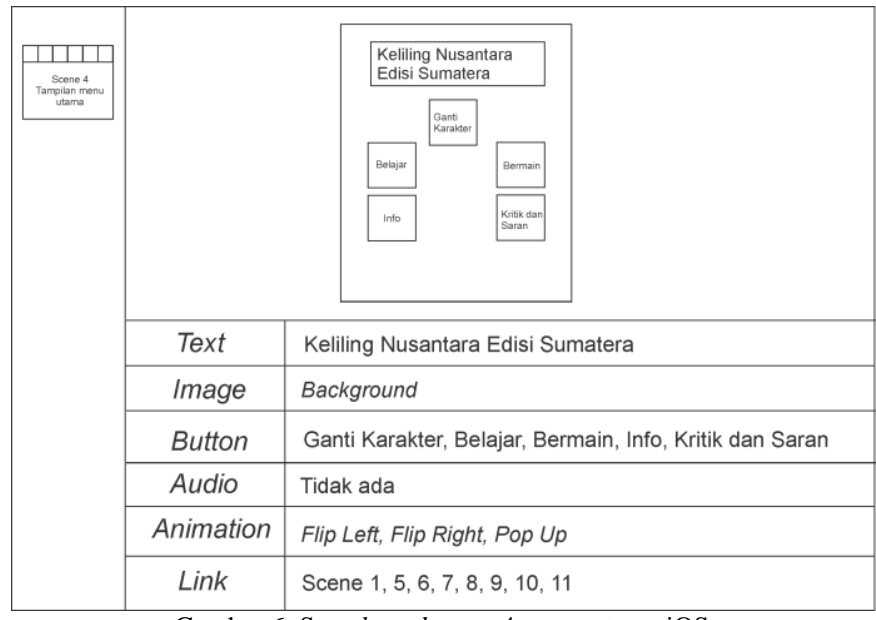

Gambar 6. Storyboard scene 4 menu utama iOS

Kemudian storyboard scene 15 untuk menu belajar pada aplikasi yang ditunjukkan gambar 7 . sebagai berikut.

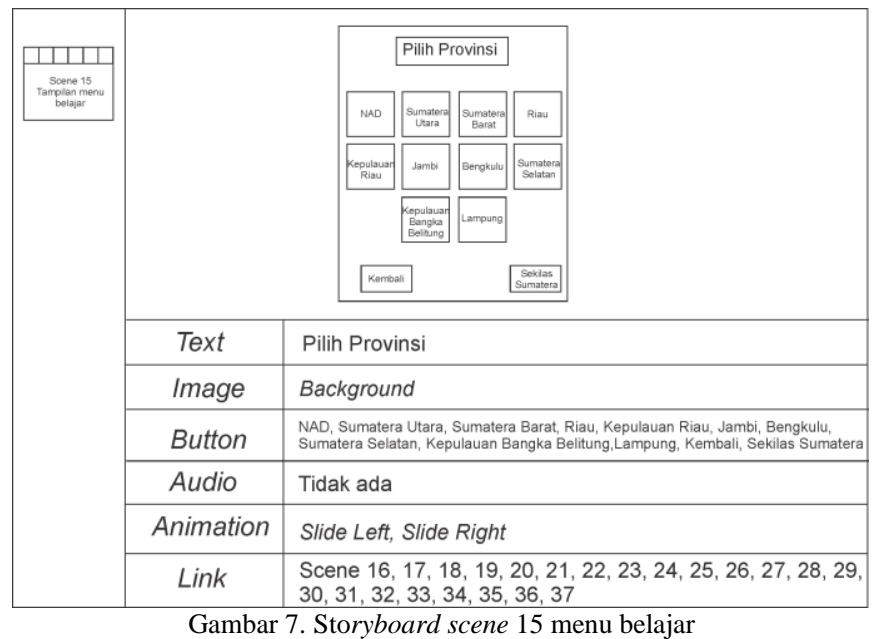

Lalu storyboard scene 179 merupakan menu berbagi aplikasi sedangkan storyboard scene 184 merupakan menu bermain pada aplikasi yang ditunjukkan berturut-turut pada gambar 8. dan gambar 9. sebagai berikut.

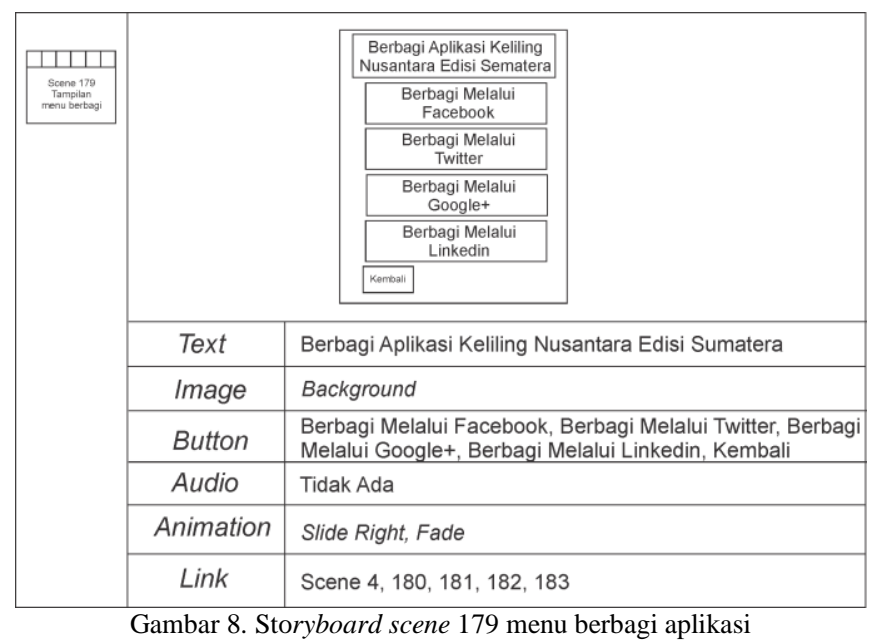




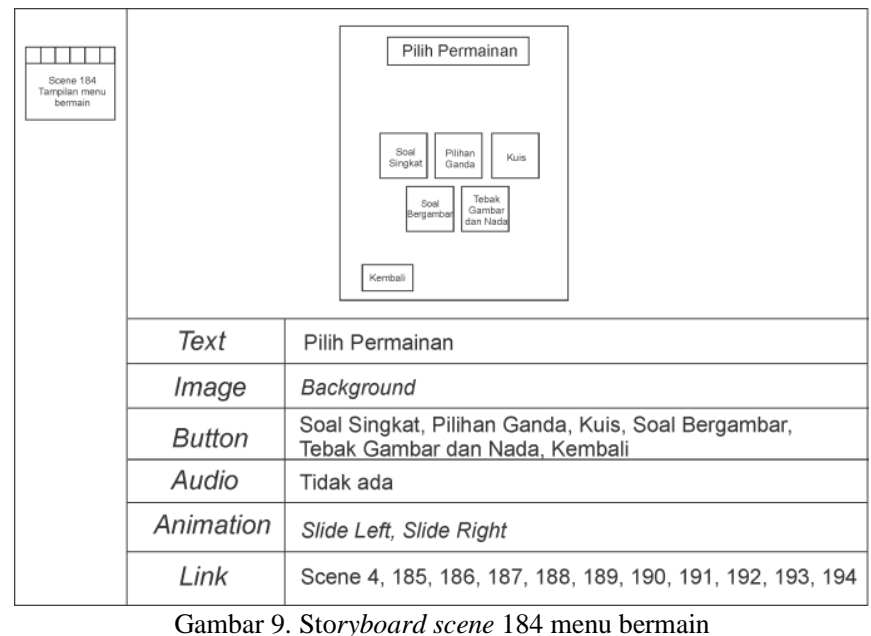

\section{Pengumpulan Materi Aplikasi}

Pengumpulan materi aplikasi merupakan tahap mengumpulkan bahan seperti gambar, animasi, suara, pembuatan citra grafik, foto dan lain-lain yang diperlukan untuk tahap pembuatan aplikasi. Pada proses pembuatan aplikasi Keliling Nusantara Edisi Sumatera berbasis Android dan iOS ini bahan-bahan yang diperlukan antara lain adalah gambar, tombol, suara dan animasi.

1. Gambar, gambar yang ada pada aplikasi berupa gambar kartun yang menarik dengan harapan minat pengguna aplikasi akan bertambah.

2. Tombol, tombol yang ada pada aplikasi berupa tombol yang dibuat jelas dan menarik sehingga menghasilkan interaksi antara pengguna dengan aplikasi.

3. Suara, suara yang ada pada aplikasi berupa suara untuk konten lagu adat, alat musik adat dan fauna khas daerah setiap provinsi.

4. Animasi, animasi yang ada pada aplikasi berupa animasi pepindahan antara scene satu dengan yang lain sehingga aplikasi menjadi lebih menarik.

\section{Pembuatan Dan Pengujian ApliKasi}

\section{A. Pembuatan Aplikasi}

Pembuatan aplikasi dimulai dengan membuat setiap scene beserta link antara scene satu dengan scene lainnya sehingga menjadi satu kesatuan. Tahap pembuatan aplikasi disesuaikan dengan proses perancangan yang telah dibuat serta menggunakan materi yang telah dikumpulkan sebelumnya. Hasil pembuatan aplikasi yang ditampilkan hanya 5 dari total keseluruhan pembuatan aplikasi yang telah dilakukan. Adapun hasil pembuatan aplikasi yang ditampilkan tersebut adalah pembuatan aplikasi untuk scene 4, scene 15, scene 179 dan scene 184. Berikut hasil pembuatan aplikasi untuk masing-masing scene tersebut.

\section{Scene 4 - Menu Utama Aplikasi}

Scene 4 merupakan menu utama aplikasi yang menjelaskan seluruh fitur yang ada di dalam aplikasi. Untuk menu utama aplikasi android memiliki 14 obyek multimedia yang terdiri dari 2 obyek teks, 1 obyek gambar, 4 obyek animasi dan 7 buah tombol sedangkan untuk aplikasi ios hanya memiliki 11 obyek multimedia yaitu 2 obyek teks, 1 obyek gambar, 3 obyek animasi dan 5 buah tombol. Hal ini dikarenakan tombol berbagi dan keluar yang terdapat pada aplikasi Android tidak digunakan pada aplikasi iOS yang dibangun. Hasil untuk pembuatan menu utama aplikasi Android dan iOS tersebut dapat dilihat berturut-turut pada gambar 10. dan gambar 11 sebagi berikut.

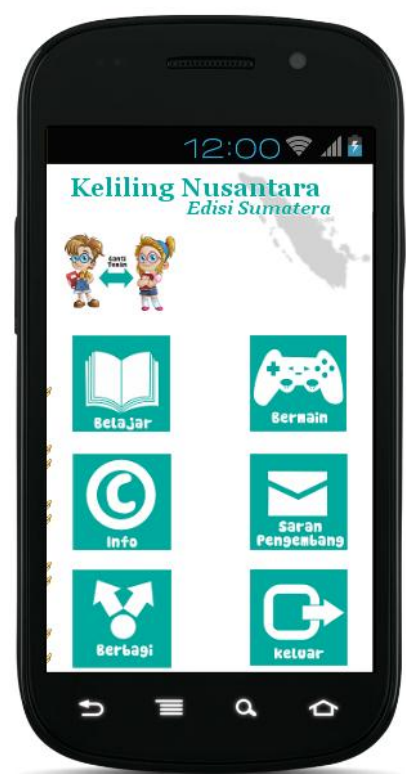

Gambar 10. Scene 4 untuk aplikasi Android

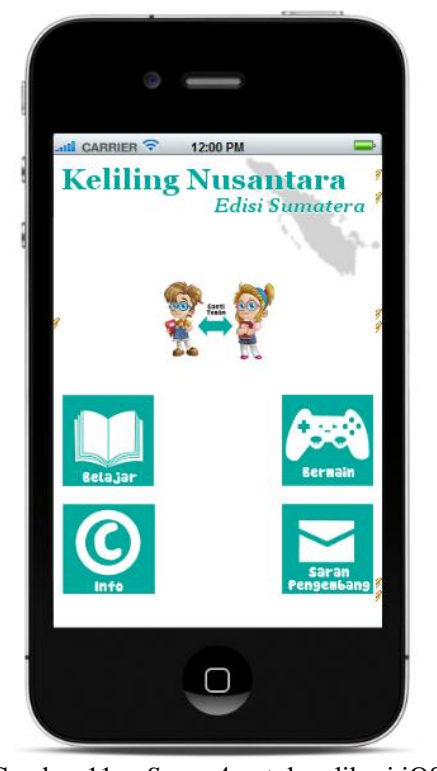

Gambar 11. Scene 4 untuk aplikasi iOS

\section{Scene 15 - Menu Belajar}

Scene ini merupakan menu belajar pada aplikasi yang berisi 10 provinsi di pulau sumatera yang dapat dipelajari seni dan budayanya. Selain itu, di menu belajar ini pengguna juga dapat mempelajari sekilas tentang pulau sumatera itu sendiri. Menu belajar ini memiliki 16 obyek multimedia yang terdiri dari 1 obyek teks, 1 obyek gambar, 2 obyek animasi dan 12 buah tombol. Hasil untuk pembuatan menu belajar tersebut dapat dilihat pada gambar 12 .

\section{Scene 179 - Menu Berbagi}

Scene ini merupakan menu berbagi link aplikasi melalui media sosial yaitu facebook, twitter, google+ dan linkedin. Menu ini memiliki 9 obyek multimedia yang terdiri dari 1 obyek teks, 1 obyek gambar, 2 obyek animasi dan 5 buah tombol. Hasil untuk pembuatan menu berbagi tersebut dapat dilihat pada gambar 13 .

\section{Scene 184 - Menu Bermain}

Scene ini merupakan menu bermain pada aplikasi yang berisi 5 permainan yang dapat dimainkan yaitu permainan soal singkat, permainan pilihan ganda, permainan kuis, permainan soal bergambar serta permainan tebak gambar dan 
nada. Menu bermain ini memiliki 10 obyek multimedia yang terdiri dari 1 obyek teks, 1 obyek gambar, 2 obyek animasi dan 6 buah tombol. Hasil untuk pembuatan menu belajar tersebut dapat dilihat pada gambar 14 .

Berikut adalah gambar 12. untuk hasil pembuatan menu belajar yang telah dijelaskan di atas.

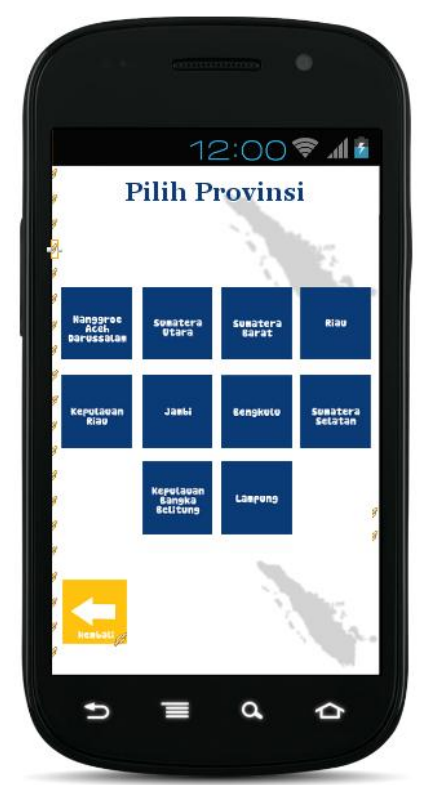

Gambar 12. Scene 15 menu belajar

Kemudian gambar di bawah ini merupakan gambar 13. untuk hasil pembuatan menu berbagi dan gambar 14. untuk hasil pembuatan menu bermain yang telah dijelaskan sebelumnya.

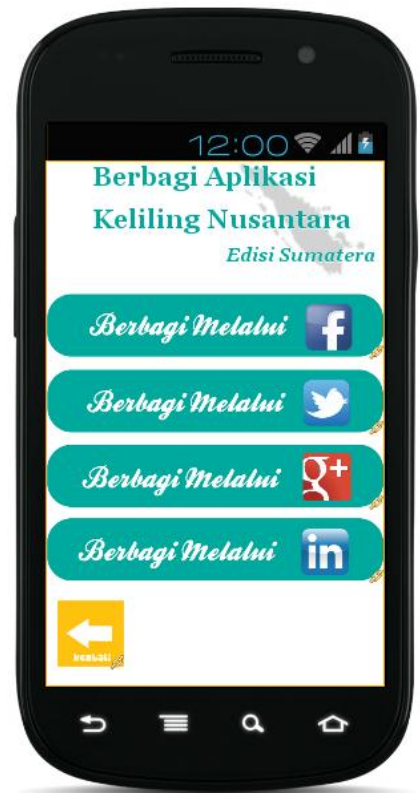

Gambar 13. Scene 179 menu berbagi

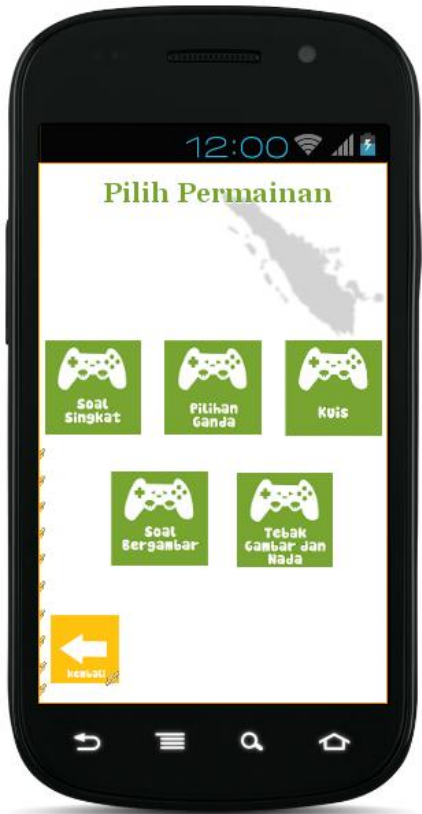

Gambar 14. Scene 184 menu bermain

\section{B. Pengujian Aplikasi}

Tujuan utama dari pengujian aplikasi yaitu untuk mengetahui dan memastikan bahwa aplikasi sesuai dengan perancangan yang telah dibuat sebelumnya sehingga aplikasi tidak memiliki kesalahan dan siap untuk digunakan.

\section{Uji Coba Aplikasi}

Pengujian aplikasi Keliling Nusantara Edisi Sumatera dilakukan dengan menggunakan metode black-box. Tahap ini berisi serangkaian pengujian fungsi dan tombol pada aplikasi. Tingkat keberhasilan pengujian, diukur dari terpenuhinya spesifikasi dan fungsionalitas kebutuhan aplikasi. Untuk aplikasi android pengujian aplikasi dijalankan pada smartphone Asus Zenfone 4 dengan sistem operasi Android 4.4.2 sedangkan untuk aplikasi iOS pengujian aplikasi dijalankan pada iPhone 4 dengan sistem operasi iOS 7.1.1. Untuk tabel pengujian aplikasi yang ditampilkan hanya 15 dari total keseluruhan pengujian yang telah dilakukan. Berikut tabel I yang berisi tentang pengujian fungsi pada aplikasi tersebut.

TABEL I

PENGUJIAN FUNGSI PADA APLIKASI

\begin{tabular}{|l|l|l|l|l|}
\hline No & \multicolumn{1}{|c|}{ Fungsi } & $\begin{array}{l}\text { Hasil Pengujian } \\
\text { Yang Diharapkan }\end{array}$ & $\begin{array}{c}\text { Hasil Pengujian } \\
\text { Aplikasi }\end{array}$ & Keterangan \\
\hline 1. & $\begin{array}{l}\text { Menampilkan } \\
\text { start screen } \\
\text { aplikasi }\end{array}$ & $\begin{array}{l}\text { Apabila aplikasi } \\
\text { dibuka maka } \\
\text { tampilan start } \\
\text { screen akan berjalan } \\
\text { dan selanjutnya } \\
\text { aplikasi akan } \\
\text { menuju ke halaman } \\
\text { awal }\end{array}$ & $\begin{array}{l}\text { Tampilan start } \\
\text { screen berjalan dan } \\
\text { aplikasi langsung } \\
\text { menampilkan } \\
\text { halaman awal }\end{array}$ & Berhasil \\
\hline 2. & $\begin{array}{l}\text { Apabila salah satu } \\
\text { menu Pilih } \\
\text { Karakter }\end{array}$ & $\begin{array}{l}\text { (ditekan), maka } \\
\text { karakter yang } \\
\text { dipilih itu akan } \\
\text { memandu pengguna } \\
\text { dalam menjalankan } \\
\text { aplikasi (sebagai } \\
\text { karakter yang } \\
\text { memberikan } \\
\text { penjelasan } \\
\text { mengenai konten } \\
\text { atau menu aplikasi } \\
\text { yang dipilih) }\end{array}$ & $\begin{array}{l}\text { Jika karakter andi } \\
\text { yang dipilih, maka } \\
\text { andi yang akan } \\
\text { memandu } \\
\text { pengguna dalam } \\
\text { menjalankan } \\
\text { aplikasi begitu juga } \\
\text { untuk karakter ana } \\
\text { yang dipilih maka } \\
\text { pemandu aplikasi } \\
\text { ialah ana }\end{array}$ & Berhasil \\
& \\
\hline
\end{tabular}




\begin{tabular}{|c|c|c|c|c|}
\hline 3. & $\begin{array}{l}\text { Menampilkan } \\
\text { menu Utama }\end{array}$ & $\begin{array}{l}\text { Apabila karakter } \\
\text { telah dipilih di } \\
\text { halaman awal maka } \\
\text { menu utama akan } \\
\text { ditampilkan }\end{array}$ & $\begin{array}{l}\text { Menu utama } \\
\text { aplikasi berjalan } \\
\text { setelah proses } \\
\text { pemilihan karakter } \\
\text { selesai }\end{array}$ & Berhasil \\
\hline 4. & $\begin{array}{l}\text { Pemilihan } \\
\text { menu Belajar }\end{array}$ & $\begin{array}{l}\text { Apabila menu } \\
\text { belajar dipilih maka } \\
\text { menu belajar akan } \\
\text { ditampilkan }\end{array}$ & $\begin{array}{l}\text { Menu belajar } \\
\text { berjalan setelah } \\
\text { tombol belajar } \\
\text { pada menu utama } \\
\text { ditekan } \\
\end{array}$ & Berhasil \\
\hline 5. & $\begin{array}{l}\text { Pemilihan } \\
\text { menu Bermain }\end{array}$ & \begin{tabular}{|l|} 
Apabila menu \\
bermain dipilih \\
maka menu bermain \\
akan ditampilkan
\end{tabular} & $\begin{array}{l}\text { Menu bermain } \\
\text { berjalan setelah } \\
\text { tombol bermain } \\
\text { pada menu utama } \\
\text { ditekan }\end{array}$ & Berhasil \\
\hline 6. & $\begin{array}{l}\text { Pemilihan } \\
\text { menu Info } \\
\text { Aplikasi }\end{array}$ & $\begin{array}{l}\text { Apabila menu info } \\
\text { aplikasi dipilih } \\
\text { maka info tentang } \\
\text { aplikasi akan } \\
\text { ditampilkan } \\
\end{array}$ & $\begin{array}{l}\text { Menu info aplikasi } \\
\text { berjalan setelah } \\
\text { tombol info pada } \\
\text { menu utama } \\
\text { ditekan } \\
\end{array}$ & Berhasil \\
\hline 7. & $\begin{array}{l}\text { Pemilihan } \\
\text { menu Saran } \\
\text { Pengembang }\end{array}$ & $\begin{array}{l}\text { Apabila menu saran } \\
\text { pengembang dipilih } \\
\text { maka tampilan } \\
\text { menu saran } \\
\text { pengembang akan } \\
\text { berjalan }\end{array}$ & $\begin{array}{l}\text { Menu saran } \\
\text { pengembang } \\
\text { berjalan setelah } \\
\text { tombol saran } \\
\text { pengembang } \\
\text { ditekan }\end{array}$ & Berhasil \\
\hline 8. & $\begin{array}{l}\text { Pemilihan } \\
\text { menu Berbagi }\end{array}$ & $\begin{array}{l}\text { Apabila menu } \\
\text { berbagi dipilih } \\
\text { maka menu berbagi } \\
\text { melalui media sosial } \\
\text { facebook, twitter, } \\
\text { google+ dan } \\
\text { linkedin akan } \\
\text { ditampilkan } \\
\end{array}$ & $\begin{array}{l}\text { Menu berbagi } \\
\text { berjalan setelah } \\
\text { tombol berbagi } \\
\text { pada menu utama } \\
\text { ditekan }\end{array}$ & Berhasil \\
\hline 9. & $\begin{array}{l}\text { Pemilihan } \\
\text { menu Keluar }\end{array}$ & $\begin{array}{l}\text { Apabila menu } \\
\text { keluar dipilih maka } \\
\text { pengguna akan } \\
\text { keluar dari aplikasi }\end{array}$ & Aplikasi tertutup & Berhasil \\
\hline 10. & $\begin{array}{l}\text { Pemilihan } \\
\text { menu } \\
\text { Nanggroe } \\
\text { Aceh } \\
\text { Darussalam } \\
\text { (NAD) }\end{array}$ & $\begin{array}{l}\text { Apabila menu NAD } \\
\text { dipilih maka menu } \\
\text { belajar seni dan } \\
\text { budaya provinsi } \\
\text { NAD ditampikan }\end{array}$ & $\begin{array}{l}\text { Menu belajar } \\
\text { provinsi nad } \\
\text { berjalan setelah } \\
\text { tombol nanggroe } \\
\text { aceh darussalam } \\
\text { pada menu belajar } \\
\text { ditekan } \\
\end{array}$ & Berhasil \\
\hline 11. & \begin{tabular}{|l} 
Pemilihan \\
menu \\
Sumatera \\
Utara
\end{tabular} & $\begin{array}{l}\text { Apabila menu } \\
\text { Sumatera Utara } \\
\text { dipilih maka menu } \\
\text { belajar seni dan } \\
\text { budaya provinsi } \\
\text { Sumatera Utara } \\
\text { ditampikan } \\
\end{array}$ & $\begin{array}{l}\text { Menu belajar } \\
\text { provinsi sumatera } \\
\text { utara berjalan } \\
\text { setelah tombol } \\
\text { sumatera utara } \\
\text { pada menu belajar } \\
\text { ditekan } \\
\end{array}$ & Berhasil \\
\hline 12. & $\begin{array}{l}\text { Pemilihan } \\
\text { menu } \\
\text { Sumatera } \\
\text { Barat }\end{array}$ & $\begin{array}{l}\text { Apabila menu } \\
\text { Sumatera Barat } \\
\text { dipilih maka menu } \\
\text { belajar seni dan } \\
\text { budaya provinsi } \\
\text { Sumatera Barat } \\
\text { ditampikan }\end{array}$ & $\begin{array}{l}\text { Menu belajar } \\
\text { provinsi sumatera } \\
\text { barat berjalan } \\
\text { setelah tombol } \\
\text { sumatera barat } \\
\text { pada menu belajar } \\
\text { ditekan }\end{array}$ & Berhasil \\
\hline 13. & $\begin{array}{l}\text { Pemilihan } \\
\text { menu Riau }\end{array}$ & $\begin{array}{l}\text { Apabila menu Riau } \\
\text { dipilih maka menu } \\
\text { belajar seni dan } \\
\text { budaya provinsi } \\
\text { Riau ditampikan }\end{array}$ & $\begin{array}{l}\text { Menu belajar } \\
\text { provinsi riau } \\
\text { berjalan setelah } \\
\text { tombol riau pada } \\
\text { menu belajar } \\
\text { ditekan }\end{array}$ & Berhasil \\
\hline 14. & \begin{tabular}{|l} 
Pemilihan \\
menu \\
Kepulauan \\
Riau
\end{tabular} & $\begin{array}{l}\text { Apabila menu } \\
\text { Kepulauan Riau } \\
\text { dipilih maka menu } \\
\text { belajar seni dan } \\
\text { budaya provinsi } \\
\text { Kepulauan Riau } \\
\text { ditampikan } \\
\end{array}$ & $\begin{array}{l}\text { Menu belajar } \\
\text { provinsi kepulauan } \\
\text { riau berjalan } \\
\text { setelah tombol } \\
\text { kepulauan riau } \\
\text { pada menu belajar } \\
\text { ditekan }\end{array}$ & Berhasil \\
\hline 15. & $\begin{array}{l}\text { Pemilihan } \\
\text { menu Jambi }\end{array}$ & $\begin{array}{l}\text { Apabila menu } \\
\text { Jambi dipilih maka } \\
\text { menu belajar seni } \\
\text { dan budaya provinsi } \\
\text { Jambi ditampikan }\end{array}$ & $\begin{array}{l}\text { Menu belajar } \\
\text { provinsi jambi } \\
\text { berjalan setelah } \\
\text { tombol jambi pada } \\
\text { menu belajar } \\
\text { ditekan } \\
\end{array}$ & Berhasil \\
\hline
\end{tabular}

Kemudian pengujian berikutnya dilakukan pada semua tombol yang ada di dalam aplikasi. Hasil pengujian tersebut dapat dilihat pada tabel II sebagai berikut.

TABEL II

PENGUJIAN TOMBOL PADA APLIKASI

\begin{tabular}{|l|l|l|l|}
\hline No & $\begin{array}{l}\text { Parameter } \\
\text { pengujian }\end{array}$ & \multicolumn{1}{|c|}{ Keterangan } & $\begin{array}{c}\text { Hasil } \\
\text { Uji }\end{array}$ \\
\hline 1. & $\begin{array}{l}\text { Tombol } \\
\text { Kembali }\end{array}$ & $\begin{array}{l}\text { Ketika tombol ditekan, pengguna dapat kembali } \\
\text { ke halaman sebelumnya sesuai dengan halaman } \\
\text { yang terhubung dengan tombol tersebut }\end{array}$ & Benar \\
\hline 2. & $\begin{array}{l}\text { Tombol } \\
\text { Berikutnya }\end{array}$ & $\begin{array}{l}\text { Ketika tombol ditekan, pengguna dapat menuju } \\
\text { ke halaman berikutnya sesuai dengan halaman } \\
\text { yang terhubung dengan tombol tersebut }\end{array}$ & Benar \\
\hline 3. & Tombol Play & $\begin{array}{l}\text { Ketika tombol ditekan, audio (suara) yang } \\
\text { terhubung dengan tombol tersebut dalam } \\
\text { keadaan on (hidup) }\end{array}$ & Benar \\
\hline 4. & $\begin{array}{l}\text { Tombol } \\
\text { Pause }\end{array}$ & $\begin{array}{l}\text { Ketika tombol ditekan, audio (suara) yang } \\
\text { terhubung dengan tombol tersebut dalam } \\
\text { keadaan off (mati) dengan kondisi pause }\end{array}$ & Benar \\
\hline 5. & $\begin{array}{l}\text { Tombol } \\
\text { Petunjuk }\end{array}$ & $\begin{array}{l}\text { Ketika tombol ditekan, pengguna dapat melihat } \\
\text { petunjuk dari permainan yang terhubung dengan } \\
\text { tombol tersebut }\end{array}$ & Benar \\
\hline 6. & $\begin{array}{l}\text { Tombol } \\
\text { Keluar }\end{array}$ & $\begin{array}{l}\text { Ketika tombol ditekan, pengguna dapat keluar } \\
\text { dari permainan dan menuju ke menu bermain }\end{array}$ & Benar \\
\hline 7. & $\begin{array}{l}\text { Tombol } \\
\text { Jawab }\end{array}$ & $\begin{array}{l}\text { Ketika tombol ditekan, jawaban yang telah } \\
\text { dipilih akan diperiksa benar atau salahnya lalu } \\
\text { akan menuju ke halaman yang terhubung } \\
\text { dengan tombol tersebut }\end{array}$ & Benar \\
\hline 8. & $\begin{array}{l}\text { Tombol } \\
\text { Main Lagi }\end{array}$ & $\begin{array}{l}\text { Ketika tombol ditekan, permainan akan diulang } \\
\text { kembali sesuai dengan permainan yang } \\
\text { terhubung dengan tombol tersebut }\end{array}$ & Benar \\
\hline 9. & $\begin{array}{l}\text { Tombol } \\
\text { Ulangi }\end{array}$ & $\begin{array}{l}\text { Ketika tombol ditekan, permainan kuis akan } \\
\text { diulang kembali ke posisi awal }\end{array}$ & Benar \\
\hline 10. & $\begin{array}{l}\text { Tombol } \\
\text { Hasil }\end{array}$ & $\begin{array}{l}\text { Ketika tombol ditekan, jawaban yang telah } \\
\text { diinputkan akan diperiksa benar atau salahnya } \\
\text { lalu akan menuju ke halaman yang terhubung } \\
\text { dengan tombol tersebut }\end{array}$ & Benar \\
\hline
\end{tabular}

\section{Uji Coba Pengguna}

Pengujian aplikasi juga dilakukan secara langsung kepada pengguna, dalam hal ini responden diambil secara acak baik itu pelajar SD, SMP, SMA, mahasiswa dan masyarakat umum. Pengujian ini dilakukan secara objektif dengan tujuan untuk mengetahui bagaimana penilaian pengguna terhadap aplikasi yang telah dibuat. Pengujian dilakukan dengan menyebarkan kuesioner baik itu hardcopy maupun softcopy hingga terkumpul sebanyak 40 sampel data dengan rincian 21 kuesioner hardcopy dan 19 kuesioner softcopy. Proses pengujian ini dilakukan dengan cara meminta responden untuk mendownload dan menginstall aplikasi lalu mengoperasikannya serta dilanjutkan dengan mengisi kuesioner tersebut. Hasil dari uji coba pengguna ini adalah sebagai berikut.

1. Responden menilai aplikasi sangat menarik

2. Responden menilai tampilan aplikasi sangat bagus

3. Responden menilai aplikasi mudah untuk dimainkan

4. Responden tertarik memainkan aplikasi ini kembali

5. Responden menilai aplikasi sangat membantu dalam mengenal seni dan budaya Indonesia di pulau Sumatera

6. Responden menilai pengetahuan seni dan budaya menjadi sangat bertambah setelah memainkan aplikasi

7. Responden menilai aplikasi sangat lancar saat dimainkan 8. Responden menilai hasil dari permainan pada aplikasi sebelum dan sesudah proses belajar dilakukan adalah berbeda 9. Responden menilai semua info aplikasi sangat benar 10. Responden menilai penggunaan gambar dan suara dalam aplikasi sangat membantu pemahaman tentang seni dan budaya Indonesia di pulau Sumatera 
Validasi dan Reliabilitas Kuesioner Menggunakan SPSS

Proses uji validasi kuesioner menghasilkan semua soal dapat dikatakan valid karena nilai signifikansi semua soal berada di bawah nilai 0.05 sedangkan untuk proses uji reliabilitas kuesioner menghasilkan nilai 0.704 yang berarti kuesioner memiliki tingkat reliabilitas yang tinggi.

\section{KESIMPULAN DAN SARAN}

\section{A. Kesimpulan}

Berdasarkan hasil penelitian dan pengujian, maka dapat diambil kesimpulan sebagai berikut.

1. Aplikasi berjalan dengan baik pada sistem operasi Android versi 2.2-4.X dan iOS versi 5-7.

2. Aplikasi berisi kekayaan seni budaya Indonesia yaitu lagu daerah beserta lirik dan suaranya, pakaian adat, rumah adat, tradisi adat, senjata adat, tarian adat, alat musik adat, lambang daerah, hari jadi, nama ibu kota, letak, luas dan jumlah penduduk serta flora dan fauna khas daerah di pulau Sumatera.

3. Aplikasi yang dibangun dapat berfungsi sebagai media pembelajaran dalam mengenal kekayaan seni dan budaya di Indonesia terutama di pulau Sumatera.

4. Berdasarkan pengujian aplikasi dengan metode blackbox, fungsionalitas aplikasi berjalan dengan baik sesuai dengan spesifikasi dan perancangan yang diinginkan.

5. Berdasarkan hasil persentase serta hasil perhitungan validasi dan reliabilitas dengan SPSS, sebanyak $89 \%$ pengguna menilai aplikasi sangat menarik, $81 \%$ pengguna menilai tampilan aplikasi sangat bagus, $77.5 \%$ pengguna menilai aplikasi mudah dimengerti dan dimainkan, 79\% pengguna menilai tertarik memainkan aplikasi ini kembali, 91\% pengguna menilai aplikasi sangat membantu dalam mengenal seni dan budaya nusantara di pulau Sumatera, $88 \%$ menilai pengetahuan tentang seni dan budaya nusantara di pulau Sumatera sangat bertambah setelah memainkan aplikasi ini, $82.5 \%$ menilai aplikasi sangat lancar saat dimainkan, $76.5 \%$ menilai hasil dari permainan pada aplikasi sebelum dan sesudah proses belajar dilakukan berbeda, $82.5 \%$ menilai semua info seni dan budaya nusantara dalam aplikasi sudah sangat benar dan sebanyak $88.5 \%$ menilai penggunaan gambar dan suara pada aplikasi ini sangat membantu dalam pemahaman mengenai seni dan budaya nusantara yang ada di pulau sumatera.

\section{B. Saran}

Saran yang diberikan dalam upaya pengembangan aplikasi Keliling Nusantara Edisi Sumatera berbasis Android dan iOS ini adalah sebagai berikut.

1. Perlu diperluas lagi konten seni dan budayanya, dibuat aplikasi per edisi pulau di Indonesia contoh Keliling Nusantara Edisi Jawa, Kalimantan, Sulawesi, Bali dan Nusa Tenggara serta Maluku dan Papua.

2. Perlu ditambahkan lagi konten permainannya sehingga aplikasi menjadi lebih menarik contoh pertanyaan seputar seni dan budaya dibuat secara acak, menambahkan permainan lain yang interaktif seperti menebak warna dari lambang daerah setiap provinsi, mencocokkan pakaian adat dengan rumah adat setiap provinsi dan sebagainya.

3. Perlu ditambahkan suara pada karakter yang menjadi pemandu aplikasi serta perlu ditambahkan video dari tarian adat dan tradisi adat setiap provinsi agar aplikasi lebih interaktif.

\section{DAFTAR PUSTAKA}

[1] Abras, Chadia, Maloney-Krichmar, Diane and Preece, Jenny, User Centered Design 2005. http://phoenix.goucher.edu/ jillz/cs325_hci/handouts/User-centereddesign-Article.doc. 10 Februari 2015, 18.00 WIB

[2] Amborowati, Armadyah, Rancangan Sistem Pameran Online Menggunakan Metode UCD (User Centered Design), Skripsi, S1, STMIK AMIKOM Yogyakarta, 2007.

[3] Widyaningsih,A.I., Membangun Aplikasi Al-Qur'an Multimedia Online Berbasis Web dan Mobile, Skripsi, S1, Universitas Komputer Indonesia Bandung, 2011.

[4] Kamohartomo, I.P., Mulyanto, Adi dan Z.A. Ahmad, Munawar, Implementasi User Centered Design Melalui Pembangunan Aplikasi yang Memanfaatkan Animasi Studi Kasus: Personalisasi Produk, Jurnal Sarjana Institut Teknologi Bandung Bidang Teknik Elektro dan Informatika Volume 1, Number 2, Juli 2012.

[5] Arifa, Nurul, Perancangan Permainan Proses Pembuatan BioEtanol Ekstrak Limbah Buah Menggunakan Adobe Flash CS3 Professional, Skripsi, S1, Universitas Diponegoro Semarang, 2014.

[6] Lestari, Dian, Perancangan Komunikasi Visual Untuk Seri Cd Interaktif "Keliling Nusantara Yuk!',Skripsi, S1, Universitas Bina Nusantara, Jakarta, 2011.

[7] Winata, Yoanda, Sukianto, G.R. dan Santoso, Anthony, Game "Petualangan Bima Mengenal Rumah Adat di Indonesia" Berbasis Android, Skripsi, S1, Universitas Bina Nusantara, Jakarta, 2012.

[8] Nugraha, A.K., Perancangan Permainan Gelembung Huruf (Tokoh Wayang) Berbasis Sistem Operasi iOS Menggunakan Gamesalad, Skripsi, S1, Universitas Diponegoro, Semarang, 2014.

[9] Safaat H., Nazruddin, Android Pemrograman Aplikasi Mobile Smartphone dan Tablet PC Berbasis Android, Informatika, Bandung. 2012.

[10] Sutopo, Ariesto Hadi, Multimedia Interaktif dengan Flash, Graha Ilmu, Yogyakarta. 2003.

[11] Nofiantoro, Arix, Analisis dan Perancangan Game "Bermain Bersama Dito \& Dola”, Skripsi S1, STMIK AMIKOM Yogyakarta, 2011.

[12] Koentjaraningrat, Pengantar Ilmu Antropologi, Rineka Cipta, Jakarta. 2009.

[13] Soekiman, D., Kebudayaan Indis, Komunitas Bambu, Depok. 2011.

[14] Ray, John. Sams Teach Yourself iPhone Application Development in 24 Hours Second Edition. New Jersey: Pearson Education, Inc., 2011.

[15] Sugiyono, Metode Penelitian Kuantitatif, Kualitatif, dan $R \& D$, Alfabeta, Bandung, 2010.

[16] Genuitec, Mobione Learning Center, Mobione Introduction 2014. http://www.genuitec.com/mobile/docs/mobiOneIntroduction/mobiOneI ntroduction.html 11 Februari 2015, 10.00 WIB

[17] Juliandani, Fenty, Makalah Sistem operasi iOS 2013. http://fentyjuliandani.blogspot.sg/2013/12/makalah-sistem-operasiios.html 20 Februari 2015, 13.00 WIB 